\title{
Ventajas comparativas y explotación de los recursos ambientales
}

\section{Diego Azqueta}

\section{Catedrático de}

Teoría Económica,

Universidad de Alcalá

\section{Daniel Sotelsek}

Profesor Titular de

Teoría Económica,

Universidad de Alcalá
En este artículo se analizan cinco tipos de comercio internacional basados en la ventaja comparativa que les proporciona a los países subdesarrollados su dotación de recursos ambientales. Se estudia, en primer lugar, la especialización de estos países en la producción de bienes y servicios altamente contaminantes. Se recuerda la especialización convencional en la producción y exportación de bienes que hacen uso intensivo de recursos naturales. Luego se incorpora la explotación financiera de los servicios recreativos de los parques naturales, y la explotación de la biodiversidad en el campo de la investigación farmacéutica. Se aborda la rentabilización de algunos servicios ambientales de estos recursos que tienen el carácter de bienes públicos y que, para traducirse en flujos financieros, requieren algún tipo de acuerdo internacional, ya sea bilateral o multilateral. En seguida, se considera el acceso de estos países en pie de igualdad a una serie de recursos globales y comunes, y, por último, el artículo se cierra con algunas conclusiones. Según ellas es difícil que las relaciones comerciales entre países en desarrollo y desarrollados, que derivan de una especialización apoyada en la dotación de recursos ambientales y naturales, aporten alguna solución a los problemas de la pobreza y la degradación ambiental. Sin embargo, una explotación más eficiente, más imaginativa y, en definitiva, más solidaria de estos recursos, podría contribuir en mucho mayor medida a la resolución de estos dos graves problemas. Para alcanzar eficiencia económica y social, en este caso, es preciso contar con la colaboración de los países adelantados, dado el carácter de bienes públicos de los recursos ambientales. 


\section{I}

\section{Introducción}

Dos de los problemas más graves a los que se enfrenta la humanidad en las postrimerías del siglo XX están cada vez más entrelazados en una economía progresivamente integrada: son el problema de la pobreza y el problema del deterioro ambiental. Si bien es cierto que la relación entre ambos está de sobra documentada (Goodstein, 1995, cap. 19), desgraciadamente no parece que el propio proceso de crecimiento en las economías subdesarrolladas, a medida que se produce, asegure su solución. En efecto, los datos empíricos muestran una evolución de los indicadores ambientales en forma de $\mathrm{U}$ : los problemas tienden a agravarse con el proceso de crecimiento hasta llegar a un punto de inflexión, a partir del cual la calidad ambiental comienza a mejorar. El quiebre en la tendencia se produce a distintos niveles de ingreso per cápita, según el indicador que se analice: suele aparecer cuando se ha alcanzado un nivel de ingreso per cápita similar al de México (Grossman y Krueger, 1995). Es más, la mejora que se produce se circunscribe a los problemas ambientales locales. En el caso de los de carácter global, el proceso de crecimiento no parece traer este tipo de posibles mejoramientos (Shafik, 1994). Es probable que ello se deba, por un lado, a razones vinculadas a los patrones de consumo que acompañan al proceso de crecimiento en sí y, por otro, al hecho de que esta dinámica se da en el marco de una economía cada vez más integrada, en la cual las corrientes de comercio internacional pueden estar facilitando este trasvase de contaminación desde las economías más desarrolladas a las más pobres. Esto es al menos lo que, desde un punto de vista teórico, muestran los estudios que han incorporado las variables ambientales en los modelos de comercio internacional (Copeland y Taylor, 1995a).

$\square$ Se han presentado versiones preliminares del presente trabajo en el Departamento de Economía de la Universidad de la República (Montevideo, Uruguay), en la Universidad de Corrientes (Argentina), en el $2^{\circ}$ Simposium Internacional de Economía realizado en el Instituto Tecnológico de Monterrey (México, D.F.), así como en el Instituto para el Ecodesarrollo de la Región Amazónica Ecuatoriana (Quito), habiéndose enriquecido notablemente con los debates consiguientes. Los autores quieren agradecer los comentarios recibidos de J.M. Naredo (Fundación Argentaria, Madrid), de P. Biffani (Ginebra), y de dos evaluadores anónimos. Finalmente, el presente trabajo ha contado con una ayuda a la investigación otorgada por la Subdirección General de Formación y Promoción del Conocimiento (Ministerio de Educación y Cultura, España).
El presente artículo pretende mostrar que las actuales relaciones comerciales entre países subdesarrollados y desarrollados, fruto de una especialización apoyada en la dotación de recursos ambientales y naturales, difícilmente aportarán una solución a los problemas de la pobreza y la degradación ambiental. Sin embargo, una explotación más eficiente, más imaginativa y, en definitiva, más solidaria de estos recursos, podría contribuir en mucho mayor medida a resolverlos. Para lograr eficiencia económica y social, en este caso, se precisa la colaboración de los países adelantados por el carácter de bienes públicos de los recursos ambientales, pero redundaría en beneficio de todos.

Analizaremos en este sentido cinco distintos tipos de comercio internacional basados en la ventaja comparativa que les proporciona a los países subdesarrollados su dotación de recursos ambientales. Examinaremos en la sección II el más obvio y cuestionado: la especialización de estos países en la producción de bienes y servicios altamente contaminantes, es decir, en el dumping ecológico. En la sección III pasaremos revista a la especialización convencional en la producción y exportación de bienes que hacen uso intensivo de recursos naturales, tanto renovables como no renovables. En ambos casos, la conclusión no es muy optimista en cuanto a la capacidad de este tipo de intercambios para resolver los problemas de la pobreza y la degradación ambiental, globalmente considerados. En la sección IV incorporaremos una posibilidad que está adquiriendo importancia creciente, sobre todo para algunos países: la explotación financiera de ciertos servicios vinculados con sus recursos naturales y ambientales y, sobre todo, los servicios recreativos de los parques naturales y la explotación de la biodiversidad en la investigación farmacéutica. En la sección V, yendo más allá de la frontera de los bienes privados ${ }^{1}$ - ya muy borrosa en el segundo caso que se menciona en la sección anterior-, abordaremos algo mucho más prometedor: la rentabilización de algunos servicios ambientales ligados a estos recursos que tienen el carác-

\footnotetext{
${ }^{1}$ Por los que se puede cobrar un precio, ya que en principio es posible excluir de su disfrute a quien no paga.
} 
ter de bienes públicos y que, para traducirse en flujos financieros, requieren de algún tipo de acuerdo internacional de carácter bilateral o multilateral. En la sección VI, en el mismo marco de los bienes públicos y de la necesidad de acuerdos internacionales, nos de- tendremos en el que probablemente sea el más promisorio de los activos ambientales con que cuentan los menos afortunados: su acceso en pie de igualdad a una serie de recursos globales y comunes. Y en la sección VII, por último, se formulan algunas conclusiones.

\section{II}

\section{El dumping ecológico}

El dumping ecológico aparece cuando un determinado país permite que sus empresas coloquen la producción a un precio que no incluye la totalidad de los costos marginales en que se ha incurrido —en este caso dejando fuera ciertos costos ambientales - gracias a una reglamentación más permisiva al respecto. A diferencia del dumping convencional, para posibilitar el ecológico se necesita intervención gubernamental, pero el resultado es el mismo: la empresa ofrece su producción por debajo del costo, obviando en este caso un impuesto pigouviano que hubiera igualado el costo privado al costo marginal social (Rauscher, 1994). En la esfera internacional, la posibilidad de que las regiones más atrasadas se especialicen en la producción de bienes altamente contaminantes es algo que no debe sorprender: los modelos teóricos que simulan el comportamiento en los intercambios internacionales de dos países representativos (el "Norte" y el "Sur"), desembocan en esta especialización (Copeland y Taylor, 1995b). A pesar de que no siempre puede darse por supuesta la racionalidad de este tipo de política comercial bajo distintas circunstancias —Rauscher (1994) muestra que no siempre la relajación de normativas ambientales es la política más adecuada para fomentar las exportaciones-, no cabe duda de que ésta es una posibilidad contemplada por distintos países, y objeto de fuertes polémicas. $^{2}$

La variable que explica este patrón de especialización no es otra que la diferencia en los niveles de ingreso per cápita y, por consiguiente, en las respectivas demandas y ofertas de contaminación. Vale la

\footnotetext{
${ }^{2}$ En efecto, mientras que algunos países subdesarrollados consideran la preocupación ambiental de los países desarrollados en este contexto como una maniobra para proteger su propia e ineficiente estructura productiva, y no dudan en referirse abiertamente a la existencia de un nuevo fenómeno, el "ecocolonialismo" (Rotillon y Tazdaït, 1996), el mismo vocablo es utilizado para denunciar la explotación de los recursos naturales de los países subdesarrollados por parte de las grandes empresas multinacionales (Ross, 1996).
}

pena, sin embargo, tratar de analizar con más detalle este punto, que a veces es presentado eufemísticamente como resultante de una diferencia en los gustos de las sociedades respectivas.

En efecto, el origen de la contaminación se encuentra, fundamentalmente, en el proceso de producción, distribución y consumo de bienes y servicios. Como la sociedad no parece dispuesta a prescindir enteramente de los frutos del progreso en aras de un entorno inmaculado, se plantea el problema de determinar el grado de contaminación óptimo; es decir, el punto en que los beneficios del proceso productivo (los bienes y servicios que proporciona) sean exactamente iguales a sus costos, incluidos los relativos al deterioro ambiental. Esto puede ilustrarse con ayuda del gráfico 1. En su eje vertical se miden, en pesos, los costos de producir, por ejemplo, energía eléctrica, y los beneficios que representa su consumo. En el eje horizontal se mide la cantidad total de energía eléctrica producida. Supongamos que las empresas productoras se enfrentan a una estructura de costos creciente, de tal manera que su curva de costos marginales (los

GRAFICO 1

El nivel óptimo de contaminación

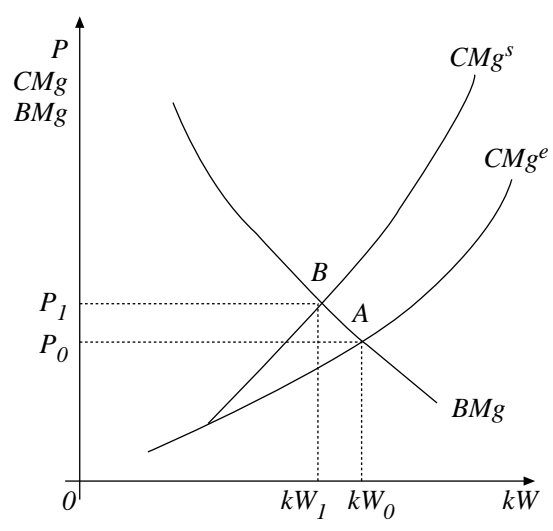

Fuente: Elaboración propia. 
costos de producir el último $\left.\mathrm{kW}: C M g^{e}\right)$ tiene la forma indicada en el gráfico. Por su parte, los beneficios marginales que deriva la sociedad del consumo de energía eléctrica (el beneficio que le reporta el último $k W$ consumido: $B M g$ ) son decrecientes, como muestra el gráfico, ya que cada vez son menos acuciantes las necesidades que se cubren con ellos. Si esto fuera todo, la sociedad debería situarse en el punto $A$, ya que prescindir de la producción de un $k W$ (situarse ligeramente a la izquierda de $k W_{0}$ ) supondría un ahorro de costos inferior al beneficio al que se renuncia, y lo contrario ocurriría si se produjera un $k W$ adicional.

Sin embargo, éste no es el final de la historia: la curva de costos analizada hasta ahora no refleja todos los costos en los que incurre la sociedad para producir (y distribuir) energía eléctrica, sino únicamente los que afectan a la empresa: faltan, al menos, los costos ambientales. Conceptualmente, no hay ninguna dificultad en introducirlos. Su efecto es de sobra conocido: se añaden a los existentes, y desplazan la curva de costos marginales hacia arriba $\left(C M g^{s}\right)$. El cambio introducido es sencillo de interpretar: el nuevo punto óptimo es ahora $B$, caracterizado por una menor producción y consumo de electricidad $\left(k W_{1}<k W_{0}\right)$, y por lo tanto menor contaminación, y un mayor precio al consumidor final $\left(P_{1}>P_{0}\right)$. Como es obvio, la magnitud del impacto dependerá de la distancia entre la vieja y la nueva curva de costos marginales (que no tienen por qué ser paralelas: probablemente se separen cada vez más, ya que los costos de la contaminación son crecientes). En otras palabras, esta divergencia depende del valor de los costos ambientales impuestos por la contaminación sobre la sociedad. No resulta fácil medir esta pérdida de bienestar, a pesar de la existencia de una serie de métodos más o menos apropiados para hacerlo (Azqueta, 1994). La Unión Europea, por ejemplo, ha completado la primera etapa de un ambicioso proyecto de investigación (Proyecto ExternE) cuyo objetivo es, precisamente, monetizar los costos generados por la contaminación ambiental en los distintos ciclos de producción de energía eléctrica (Comunidad Europea, 1995). ${ }^{3}$

Pero con independencia de las dificultades de cálculo, algo sí queda claro en estos estudios: el valor de la pérdida de bienestar originada por la contamina-

\footnotetext{
${ }^{3}$ Este proceso de valoración de los activos ambientales (o de su pérdida) supone reducirlos a la categoría de mercancías. No es que haya nada intrínsecamente malo en las mercancías: sólo que la relación que establece la persona con respecto a ellas (y que se traduce en el hecho de que estaría dispuesta a cambiarlas por la cantidad de dinero que mantuviera su nivel de bienestar inalterable) no es la que mucha gente consideraría adecuada para representar las relaciones del ser humano con la naturaleza (Anderson, 1993,
}

ción parece ser mayor cuanto mayor es el nivel de ingreso de la población afectada. Esto es particularmente evidente, por ejemplo, cuando se trata del impacto de la contaminación sobre la vida y la salud de las personas, al aumentar por ejemplo las tasas de morbilidad y mortalidad del colectivo afectado; el valor de una "vida estadística" es menor, en términos generales, cuanto menor es el ingreso de los sectores afectados. Este es, precisamente, el argumento que justificaría el dumping ecológico; dado que los países o regiones más atrasados tienen un menor nivel de ingreso, el costo de la pérdida de calidad ambiental es en ellos menor (la curva de costos marginales se desplaza hacia arriba en menor medida) y, por tanto, la producción de bienes altamente contaminantes resultaría más barata. En definitiva, parecería que el deterioro del medio ambiente causaría una menor pérdida de bienestar en los países o regiones pobres que en los ricos, y eso les daría una ventaja comparativa. De ser cierto lo anterior, la producción y exportación de bienes y servicios de alta contaminación se justificaría, en principio, siempre y cuando ésta fuera estrictamente local (de otro modo se estarían generando externalidades negativas en contra de quienes no se benefician del proceso) y limitada en el tiempo, no acumulativa, ya que de no ser así se estaría actuando en contra de las generaciones futuras. ${ }^{4}$

Sin embargo, y como resulta obvio, el argumento es demasiado problemático como para ser aceptado sin más:

i) El hecho de que la contaminación "valga" menos entre los estratos desfavorecidos de la población se explica porque la mayoría de los métodos empleados para descubrir el valor del daño causado, lo que hacen es intentar averiguar si la gente está dispuesta a pagar por evitarlo. Ahora bien, como es de sobra conocido, lo que uno está dispuesto a pagar por algo de-

cap. 9). En otras palabras, la valoración convencional se mueve en el campo de los valores de cambio, dejando fuera, entre otros, los "valores no compensables" que podrían ser modelizados a través de un orden lexicográfico, pero no monetario (Lockwood, 1997). Volveremos sobre este punto al final del trabajo.

${ }^{4}$ No es del todo válido el argumento de que se podría compensar a las generaciones futuras con la inversión en su favor de parte correspondiente de los beneficios generados en el proceso, sustituyendo capital natural por capital producido; no siempre es posible esta sustitución, y nadie les ha preguntado, ni puede hacerlo, si estarían de acuerdo con ella. Es más, no tendría sentido hacerlo, porque son ellas las que van a ser sustituidas: va a ser un distinto grupo de personas el que formará parte de la generación futura si se contamina, que el que la hubiera formado si no se contamina. Estamos en presencia del llamado "problema de la indeterminación" (Elliot, 1995, p. 3), que el análisis económico convencional sortea gracias a que en el marco de la filosofía utilitarista que le subyace, lo que importa es la suma total de placeres y dolores, con independencia de los sujetos particulares que los experimenten. 
pende, entre otras cosas, de lo que uno puede pagar (la demanda de un bien depende del ingreso de la persona), y como los que no tienen no pueden pagar, la degradación ambiental vale menos. El problema, por lo tanto, es paralelo al del trabajo infantil en los países subdesarrollados; sin pretender defender posturas que tienen mucho de hipócritas, lo cierto es que apoyar un proceso de crecimiento en elementos como los mencionados no sólo puede considerarse una verificación clamorosa de nuestro fracaso como sociedad. Sacrificar la salud tanto física como mental de la población más desfavorecida no debería ser la solución al problema de la pobreza. La "ventaja comparativa" de las regiones subdesarrolladas con respecto a la contaminación descansa pues en un supuesto éticamente muy poco defendible. Lo mismo puede decirse, por cierto, de aquellos casos en los que esta especialización viene explicada no ya por la diferencia en las respectivas "demandas" sociales de contaminación (se supone, al contrario que en el caso anterior, que son las mismas), sino por el hecho de que en los países subdesarrollados el gobierno no refleja estas preferencias, mientras que en los desarrollados sí (Chichilnisky, 1994): también representan un punto de partida éticamente inaceptable, aunque por lo menos en lo que concierne a la primera parte del argumento, probablemente bastante realista.

ii) El enfoque adoptado para justificar este menor valor registrado de la degradación ambiental en los países atrasados incurre en el error de no computar toda una serie de efectos externos de esa degradación, que no quedan recogidos en los métodos de valoración, pero que también determinan el valor del daño; las personas pueden verse forzadas a aceptar condiciones ambientales peores por la necesidad de trabajar, pero esto afectará no sólo a su propia salud (y a la de sus vecinos), con los gastos consiguientes para la salud pública y/o la pérdida correspondiente de capital humano, sino a la durabilidad de la infraestructura urbana, a los gastos de mantenimiento y limpieza de los bienes muebles e inmuebles, a la productividad de las explotaciones de agricultura y silvicultura cercanas, etc. (Azqueta, 1994, capítulo 10). Es muy improbable que la persona afectada recoja todos estos efectos indirectos de la contaminación en su evaluación de los costos que para ella supone: habría que aplicar una serie de métodos indirectos de valoración, bien calibrados, que incluyeran todas estas externalidades. Analizando pues los costos de esta especialización para el país como un todo, y no sólo para los directamente afectados, estas "ventajas comparativas" podrían verse sensiblemente reducidas.

iii) Finalmente, proceder de esta forma supone reducir la salud de las personas a la calidad de mercancía: un bien que se consume de forma individual, exclusiva, en función del poder adquisitivo, y que es intercambiable por una determinada cantidad de dinero. Un bien, en definitiva, cuya producción y distribución se deja en manos del mercado (Anderson, 1993). Es poco probable que pueda aceptarse, desde una perspectiva ética, la consideración social de la salud como tal mercancía; lo probable es que la sociedad prefiera, al menos idealmente, una solución distinta.

En resumen, el dumping ecológico no tiene mejor justificación que la que pueda tener el trabajo infantil. No es una solución éticamente aceptable al problema de la pobreza y, desde luego, no parece apuntar a resolver los problemas ambientales.

\section{III}

\section{La explotación de los recursos naturales}

Englobamos en esta sección lo que la literatura convencional suele considerar como recursos naturales, tanto renovables como no renovables: "todos los atributos de la tierra, vivos o inanimados, que explota el hombre como fuente de alimentos, materias primas y energía". 5

\footnotetext{
${ }^{5}$ Una definición con la que Reed (1994), de quien está tomada la cita, no se muestra del todo de acuerdo, ya que no incluye "regalos" como el aire puro y la naturaleza virgen. Es, no obstante, muy conveniente para nuestro propósito, ya que dichos "regalos" serán precisamente objeto de análisis en los epígrafes siguientes.
}

En este segundo caso, las áreas deprimidas que tengan la suerte de poseer algún recurso natural podrían alcanzar una ventaja comparativa (incluso absoluta) en la producción de bienes y servicios intensivos en la utilización del mismo. Esto es tan evidente que no vale la pena detenerse más en ello, salvo quizá para recordar algunos aspectos, no menos obvios, con respecto a los límites que tanto la mera eficiencia como la equidad imponen a la explotación de los mismos. Dividiremos para ello el análisis en dos grandes apartados: 


\section{Recursos renovables}

Los recursos renovables plantean un problema sencillo sólo en apariencia. Dos de los casos más representativos probablemente sean las pesquerías y los bosques, y a ellos nos vamos a referir. El análisis de ambos brindará la oportunidad adicional de percibir algunos de los problemas que supone el régimen institucional de acceso a su disfrute.

La gestión de una pesquería, dentro del sistema de mercado, buscará maximizar el valor presente de la corriente de flujos monetarios netos que su explotación comercial acarrearía, desde una perspectiva exclusivamente financiera; es decir, comercializando la biomasa capturada, que es lo que un mercado valora. Supongamos que la tasa de crecimiento de esta biomasa ( $x=$ $d x / d t$ ) es una función positiva de su tasa de crecimiento intrínseca $[H(x)]$ y de la tasa de extracción $(y)$, función a su vez de los costos de captura $(C)$ y de los precios esperados del producto de la pesca $(P)$ :

$$
\dot{x}=H(x)-y
$$

El gráfico 2 representa gráficamente la situación planteada.

A partir de esta ecuación de comportamiento, y si el recurso es de libre acceso, los agentes económicos (empresas pesqueras) tratarán de resolver un problema de maximización condicionada, en el que la variable de control es el esfuerzo pesquero $(y)$, cuyo valor óptimo viene dado en función de los costos de extracción de la biomasa $(C)$ y de los precios esperados de la misma $(P)$. Cuando esta relación no es muy elevada $\left[(P / C)_{0}\right]$, el recurso podría gestionarse de forma sustentable, ya que el nivel de capturas óptimo es potencialmente compatible con tasas positivas de crecimiento del banco pesquero. Sin embargo, cuando ello

GRAFICO 2

\section{Explotación óptima de un recurso renovable con libre acceso}

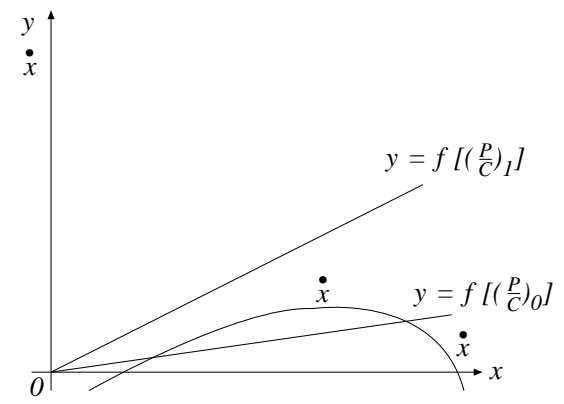

Fuente: Swanson (1994). no ocurre $\left[(P / C)_{]}\right]$, la búsqueda del máximo beneficio financiero impedirá alcanzar este equilibrio, y el recurso tenderá al agotamiento: las elevadas tasas de extracción impedirán su regeneración natural.

Analicemos ahora el caso de un bosque gestionado bajo alguna forma de propiedad, privada o común, que, impidiendo el libre acceso a él, permita una planificación de su ritmo de explotación como depósito renovable de madera, que tenga en cuenta el futuro. El problema de maximización condicionada se plantea ahora, claramente, en un contexto intertemporal, en el que la variable objetivo es el valor presente neto (VPN) del flujo de rendimientos que la explotación del recurso generará a lo largo de toda su vida útil. Respetando las ecuaciones de comportamiento anteriores y adaptando la nomenclatura al caso presente, el problema que se plantea es el de:

$$
\max \int_{0}^{t}[P(y) y-C(x) y] e^{-r t} d t
$$

sujeto a

$$
\dot{x}=H(x)-y
$$

siendo $P$ el precio esperado de la madera, $C$ su costo de extracción y $r$ la tasa de rentabilidad del capital en el sistema financiero.

La aparición de un costo de oportunidad para el capital invertido ( $r$, que actúa como tasa de descuento para la actualización del valor de los flujos en el tiempo, puede tener como consecuencia indeseada el que resulte no rentable la gestión sustentable del recurso, si su crecimiento vegetativo es relativamente lento, como muestra el gráfico 3 (Swanson, 1994). En efecto, la tasa interna de rendimiento (TIR) que ofrecería una explotación sustentable del activo, en este segundo caso, se encuentra sistemáticamente por debajo del costo de oportunidad del capital. No es el libre acceso, como en el caso precedente, el que imposibilita ahora el mantenimiento del recurso, sino el hecho de que la rentabilidad del capital natural (medida por la tasa de crecimiento biológico de la madera, suponiendo que su precio es constante) no puede competir con las alternativas que ofrece el sistema financiero. ${ }^{6}$

\footnotetext{
${ }^{6} \mathrm{El}$ resultado al que puede llegarse en los dos casos analizados muestra la importancia de los aspectos institucionales de la explotación; la inseguridad en la tenencia de la tierra, por ejemplo, reduce el valor del límite superior de la integral ( $t$ ) en la ecuación (2), al reducir el horizonte temporal relevante para el decisor, haciendo menos rentable la inversión cuyos rendimientos aparecen a mediano y largo plazo (la forestal), en favor de aquella que produce mayores rendimientos a corto plazo (la conversión del terreno para uso agrícola o ganadero), aunque esta opción, en conjunto, produce rendimientos inferiores (Gottfried, Brockett y Davis, 1994).
} 
GRAFICO 3

\section{La tasa de explotación óptima en el tiempo de un recurso renovable de propiedad privada}

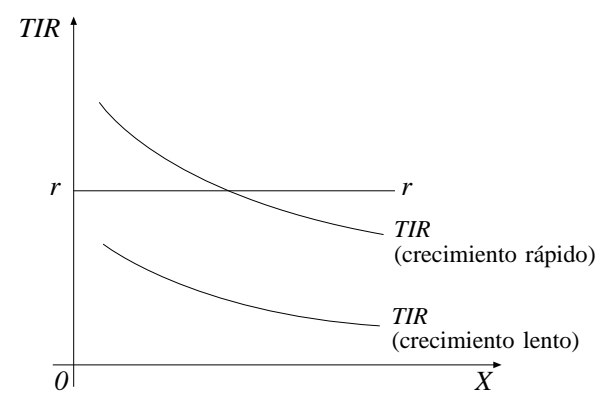

Fuente: Swanson (1994).

En muchas ocasiones, las propias circunstancias macroeconómicas de los países subdesarrollados agravan estos problemas. En efecto, la escasez de divisas que resulta del desequilibrio estructural de la balanza de pagos (reflejada en un muy elevado precio de cuenta de las divisas) lleva al sector público a adoptar una serie de medidas que favorecen la explotación financiera de los recursos naturales para su exportación, ya que a corto plazo ésta ayuda a resolver el problema, aunque desde el punto de vista económico no sea la opción más rentable (por las externalidades negativas que genera y por su costo de oportunidad), y a mediano plazo sea ambientalmente nociva y ecológicamente insostenible (Azqueta, 1992). ${ }^{7}$ Conviene, a la luz de lo anterior, analizar brevemente la polémica que ha desatado la adopción por una serie de países subdesarrollados de medidas restrictivas al comercio de determinados productos naturales (Lee, 1996).

El que algunos países en desarrollo prohibieran las exportaciones de madera en bruto, por ejemplo, ha sido cuestionado por los países importadores, aduciendo una pretendida mayor eficiencia ambiental (Anderson, 1996). En efecto, los países desarrollados, con mejor

\footnotetext{
${ }^{7} \mathrm{El}$ incremento experimentado por la demanda de carne de vacuno en los países desarrollados llevó a que en Costa Rica, por ejemplo, las tierras dedicadas a pastizales aumentaran en $3.5 \%$ por año en 1965-1990, en muchos casos con el apoyo de la financiación exterior y los programas de ayuda al desarrollo. Esto trajo como consecuencia la pérdida progresiva de bosque tropical (su superficie disminuyó $2.8 \%$ anualmente en el mismo período), con la consiguiente deforestación, y la pérdida del $50 \%$ de la superficie dedicada a la agricultura tradicional (ecológicamente sostenible), con la correspondiente caída del empleo y la producción y el aumento de las deficiencias nutricionales de la población local (Pearce y Warford, 1993)
}

tecnología y mano de obra más calificada, son más eficientes en la utilización de la madera como materia prima en el proceso de producción, por lo cual el comercio de la madera en bruto permite reducir la cantidad de madera utilizada por unidad de producto final. Por otro lado, el abaratamiento de los precios locales de la madera que la prohibición supone puede acrecentar su uso y hacerlo más ineficiente, si no está compensado por una adecuada política de licencias de extracción; esta apreciación, sin embargo, se apoya en argumentos de muy corto plazo (casi un análisis de eficiencia estática comparativa), y no tiene en cuenta los efectos dinámicos sobre el desarrollo de una política que permita retener las operaciones que generan mayor valor agregado (Goodland y Daly, 1996). ${ }^{8}$ En el mediano y largo plazo, el beneficio ambiental de este proceso de generación de ingresos y empleo que la prohibición supone probablemente sea mayor que el efecto de la pérdida de eficiencia a corto plazo. La prohibición de exportar ha de venir acompañada, en todo caso, de algún tipo de alternativa económica. La prohibición pura y simple de comercializar la madera, lejos de preservar el recurso, generalmente conspira contra él, cuando ya se ha producido o se está produciendo la ocupación del territorio: la rentabilidad de las explotaciones forestales baja con relación a la de las explotaciones agrícolas o ganaderas en el mismo territorio, al reducir el valor de $P$ en la ecuación (2), lo que incentiva el desmonte del bosque para su cultivo o explotación ganadera. Para adoptar este tipo de medidas, por lo tanto, hay que efectuar antes un cuidadoso análisis institucional de la situación. En este sentido, los certificados de origen de la madera, que garantizan la sustentabilidad de las explotaciones de procedencia, ${ }^{9}$ podrían resultar una mejor alternativa que la prohibición sin más. Conviene, en cualquier caso, contemplar esta posibilidad en su verdadera perspectiva: como Gottfried, Brockett y Davis (1994) han señalado, el manejo forestal sustentable (que por lo menos salva el bosque secundario, ya que no el primario)

\footnotetext{
${ }^{8}$ Indonesia, uno de los principales exportadores de madera en bruto durante los años setenta (llegó a exportar el 40\% del total mundial), introdujo la prohibición en 1985, invocando el Artículo XX del Acuerdo General de Aranceles Aduaneros y Comercio (GATT). A mediados de los ochenta, estas exportaciones prácticamente habían desaparecido, mientras que las exportaciones de productos de madera alcanzaban los 3800 millones de dólares en 1991 (Goodland y Daly, 1996). Una visión más negativa de los efectos medioambientales de esta sustitución expone Anderson (1996).

${ }^{9}$ Al estilo del Forest Stewardhip Council con base en Oaxaca (México).
} 
exige una gran extensión de terreno por familia para garantizar un ingreso aceptable, lo que arroja serias dudas sobre la posibilidad de garantizar de esta manera un medio de vida satisfactorio a toda la población de la zona.

En todo caso, debe tenerse presente que la explotación financiera de una serie de recursos naturales en virtud de su valor de mercado, aunque sea sustentable, no toma en cuenta las externalidades ambientales que genera el recurso. Estas, que pueden llegar a tener un valor económico muy superior, suelen ser incompatibles con este tipo de explotación. Atender exclusivamente a los valores que proporciona el mercado no garantiza, por lo tanto, que la explotación del recurso sea socialmente óptima.

\section{Recursos no renovables}

Los recursos no renovables, por definición, no pueden explotarse de manera sostenible. Lo que se busca en este caso es repartirlos bien entre todos: un problema de equidad intergeneracional. Es costumbre acudir para esto a la llamada "regla de Hotelling", que relaciona el ritmo de explotación del recurso con su precio y con el tipo de interés (Gómez, 1994). Puede que no sea una regla muy útil para resolver el problema en la práctica, pero sí lo es para plantearlo mejor, ya que pone de relieve que los recursos no renovables tienen un costo de oportunidad que ha de añadirse al de extracción a la hora de decidir la velocidad a la que han de ser explotados. Este costo de oportunidad debe ser computado para determinar rigurosamente los beneficios netos de su explotación, aunque la contabilidad nacional convencional no lo haga y falsee por tanto las cifras sobre la rentabilidad de su explotación y las tasas de crecimiento del ingreso nacional resultantes. Vale la pena mencionar, en este sentido, la práctica que parece estar abriéndose paso en el seno del Banco Mundial, y que consiste en calcular los costos de la inversión necesaria para sustituir, en un proyecto o programa alternativo, los servicios que hubieran proporcionado los recursos no renovables explotados (Von Amsberg, 1993). ${ }^{10}$

\footnotetext{
${ }^{10}$ Es curioso comprobar que los precios de los recursos no renovables, que deberían mostrar una tendencia ascendente con el paso del tiempo, precisamente como resultado del aumento de sus rentas esperadas motivado por su creciente escasez, no parecen comportarse de esta forma. Una interesante explicación del fenómeno parte, precisamente, de la relación existente entre algunos de estos recursos y la contaminación global que su utilización genera (el caso de los combustibles fósiles): los límites establecidos a la emi-
}

Por otra parte, se hace necesario asimismo tener en cuenta los impactos ambientales de la propia explotación. El ya mencionado estudio de la Comunidad Europea (1995) sobre los costos ambientales de la generación de energía eléctrica es un excelente ejemplo del camino a seguir. Por ejemplo, la extracción de petróleo en determinados bosques tropicales tiene un impacto ambiental que no se ciñe a las operaciones propias de la empresa explotadora, no desdeñables, sino que va mucho más allá, de la mano de la colonización concomitante que resulta ser una amenaza mucho peor para la sustentabilidad del bosque primario. Este fenómeno invita no sólo a computar el impacto como uno de los precios a pagar por la extracción del crudo, sino a intentar evitarlo. Para ello habría que incidir sobre las causas últimas del fenómeno, buscando mejorar las condiciones de vida y trabajo en las regiones de origen de los potenciales emigrantes, para intentar frenar este flujo. La lección que la economía del desarrollo recibió de las funciones de migración de Todaro, y del análisis del sector informal, en el sentido de que la creación de puestos de trabajo en el sector formal urbano probablemente agrave los problemas de desempleo en lugar de solucionarlos, podría ser de estricta aplicación también en este caso: determinadas inversiones sociales y de infraestructura en la zona de explotación podrían empeorar la situación, al mejorar las expectativas de inmigrantes potenciales. ${ }^{11}$

Se trata, en definitiva, de resolver un problema que se podría resumir, simplificando mucho, en la necesidad de calcular la tasa social de interés con la cual descontar el flujo neto de rendimientos que proporciona la explotación de los recursos no renovables, y que se aspira a maximizar. Desde luego, el problema no es sencillo: se trata, en definitiva, de una cuestión de equidad intergeneracional en presencia de incertidumbre e irreversibilidad. ${ }^{12}$

sión de contaminantes ligados a su uso pueden hacer que los recursos queden inhabilitados antes de su agotamiento físico, lo que se reflejaría en la evolución señalada de sus precios esperados (Berck y Roberts, 1996).

${ }^{11}$ En el caso de la Amazonia ecuatoriana, es probable que los fondos que el ECORAE obtiene de las compañías petroleras, y que debe invertir para conseguir el desarrollo sustentable de la zona, consigan en mayor medida este objetivo si se invierten en la región de Loja, a muchos cientos de kilómetros de distancia, que invirtiéndolas en la propia Amazonia. De esta forma se podría intentar frenar un flujo migratorio de colonización ya muy considerable (de hecho, una de las principales ciudades de la zona, Lago Agrio, se conoce ya como Nueva Loja), y que la mejora de las condiciones de vida y trabajo en la Amazonia no haría sino acelerar.

12 Véase, por ejemplo, Sterner (1994) y Weitzman (1994). 


\section{IV}

\section{La explotación de algunos servicios ambientales}

Ciertos servicios ambientales de la biosfera exhiben las propiedades de los bienes públicos (no exclusión y no rivalidad en el consumo) matizadas quizá por la presencia de congestión. La intervención administrativa, sin embargo, puede imponer la exclusión en el disfrute de sus servicios, y permitir en consecuencia la aparición de un precio para ellos. Es el caso de los servicios recreativos de un determinado entorno (un parque natural, por ejemplo) para acceder al cual se cobra una entrada; de las posibilidades de investigación que ofrece la biodiversidad existente en una determinada reserva natural; o del alquiler de un territorio concreto como depósito o vertedero de los desechos, incluso tóxicos y peligrosos, que el mundo desarrollado no quiere. Teniendo en cuenta las similitudes existentes entre esto último y lo expuesto al examinar el dumping ecológico, que sería también de aplicación aquí, el análisis que sigue se limitará a los dos primeros casos mencionados. ${ }^{13}$

\section{La explotación recreativa de los parques naturales}

Los parques naturales están adquiriendo cada vez más importancia como foco de atracción de un tipo de turismo muy particular, que busca precisamente lo que la naturaleza no intervenida ofrece. En efecto, la presencia de los amantes de la naturaleza en el entorno que quieren visitar genera un efecto multiplicador sobre la economía de la zona (servicios de transporte,

\footnotetext{
${ }^{13}$ Defender la exportación de basura a los países subdesarrollados con argumentos como los mencionados en el epígrafe relativo al dumping ecológico puede tener consecuencias muy negativas: "la colisión entre el aparente buen sentido económico y la moralidad se hizo desagradablemente evidente en 1992 para Lawrence Summers, economista jefe del Banco Mundial. Un memorándum interno del Banco Mundial firmado por Summers apoyaba la idea de que podría ser racional en términos económicos para los países en desarrollo imponer unos estándares medioambientales algo más laxos que los países ricos y que esto podría darles una ventaja comparativa de hecho en algunas industrias contaminantes. El texto del memorándum fue filtrado a la prensa generando una oleada de mala publicidad (la revista People incluyó a Summers en la lista de los principales enemigos del medio ambiente). En diciembre de ese año parecía que la controversia sobre ese memorándum había bloqueado un esperado nombramiento de Summers como consejero económico jefe del presidente Bill Clinton" (Krugman y Obstferd, 1995, p. 91).
}

alojamiento y otros), que no es nada desdeñable. En Costa Rica, por ejemplo, en 1991 los parques naturales atrajeron medio millón de visitantes que generaron más de 330 millones de dólares en divisas, convirtiéndose así en la segunda mayor industria del país (Grey, 1995, p. 5). Además, a diferencia de otros activos naturales buscados con el propósito de disfrutar el ocio, estos son valorados por su carácter no intervenido, por lo que los estudios de demanda tienden a mostrar que el visitante es muy sensible a todo aquello que, como la congestión o la excesiva comercialización, alteren este disfrute (Dixon, Scura y Van't Hof, 1995; Shah, 1995).

El análisis económico permite descubrir al menos tres fuentes de valor directo para estos activos:

i) Un valor financiero para los dueños de los terrenos aledaños, que pueden servir de base para las operaciones de explotación turística y que se verán revalorizados en consecuencia. Otros propietarios, en cambio, pueden verse perjudicados si la protección del entorno supone la imposibilidad de seguir realizando una serie de actividades económicamente lucrativas (cultivo, caza, ganadería, etc.).

ii) Un valor económico para toda la sociedad, derivado del efecto multiplicador que estas operaciones tienen sobre los ingresos y el empleo en la zona (suponiendo que no estamos en presencia de un juego de suma cero) o en el país en general. Por ende, también se verán favorecidos los presupuestos públicos gracias al incremento de ingresos que genera el aumento de la actividad económica, pero en este caso se trata de un impacto meramente redistributivo.

iii) El valor propiamente recreativo que surge del bienestar que experimentan los visitantes, y que queda reflejado en el valor del excedente neto del consumidor, tal y como lo descubren, por ejemplo, los métodos del costo de viaje o de valoración contingente (Azqueta y Pérez, 1996).

El problema que se le plantea al gestor de estos espacios, buscando maximizar su valor social, es por lo tanto el de encontrar un difícil equilibrio entre la rentabilidad financiera pública y privada (en el mediano y largo plazo), el efecto multiplicador sobre el empleo y los ingresos de la economía y la preservación de las funciones ecológicas esenciales del entorno (el mantenimiento de la biodiversidad, por ejemplo). Todo 
ello, además, sin perder de vista los intereses de la población local, que normalmente resulta perjudicada por la protección del espacio (ya que se le restringen actividades en él y el acceso a recursos tradicionalmente utilizados), sin que el impacto multiplicador la beneficie (normalmente los efectos quedan en los grandes núcleos urbanos de acogida). En este sentido, la presencia comprobada de un sustancial excedente neto del consumidor entre los visitantes permite intentar traducir este valor (una disposición a pagar positiva por el disfrute de los servicios recreativos del entorno) en un flujo de recursos financieros (mediante el cobro de una entrada, por ejemplo) que podría revertirse en favor de aquella parte de la población local que resulta perjudicada.

Desgraciadamente, determinadas políticas de conservación, bien intencionadas, pueden resultar claramente perjudiciales tanto para los habitantes del entorno como para el objetivo mismo de la conservación. Puede ser el caso, por ejemplo, de la inclusión de determinadas especies en el Apéndice I del Convenio sobre Comercio Internacional y Especies Protegidas (CITES), que prohíbe todo comercio de sus productos: los resultados de la medida deben ser analizados con mucho cuidado. En efecto, cuando la especie así protegida compite con otras que no lo están, el resultado final puede ser contraproducente, ya que la medida disminuye el valor financiero de la especie amenazada en relación con el de sus competidoras: se está reduciendo su valor de uso para la población local, por intentar salvar un valor de existencia que es global. Si las dos especies (por ejemplo, elefantes y ganado) compiten por el territorio, la población local está siendo incentivada a desplazar a los elefantes, que no tienen valor de uso, para dejar paso a su ganado, que sí lo tiene. Ya vimos con anterioridad que lo mismo puede ocurrir con la prohibición de exportar determinados tipos de madera. Si la especie no protegida es un depredador natural de la especie protegida, la prohibición elimina el valor financiero de esta última, haciendo menos rentable su protección, fenómeno que se agudiza si el depredador tiene un valor financiero (Swanson, 1993; Schulz, 1996). ${ }^{14}$

\footnotetext{
${ }^{14}$ Barnes (1996) ha llevado a cabo un interesante estudio sobre los posibles efectos de la inclusión en esta lista de los elefantes, en Bostwana. Teniendo en cuenta tanto el costo de oportunidad de las tierras ocupadas por los elefantes, como los costos de protección que repercuten sobre la administración (vigilancia, control, etc.), plantea cuál sería la estrategia óptima en la gestión de este recurso. Utilizando para ello el marco de la evaluación social de proyectos, e introduciendo los correspondientes precios de cuenta, llega a la
}

Lo anterior puede formalizarse sobre la base del gráfico 4 (similar al gráfico 2). En efecto, la función de crecimiento del recurso $H(x)$ depende de una serie de variables, no representadas en el gráfico 4 debido a la introducción implícita de una cláusula caeteris paribus, pero que obviamente influyen en la evolución del recurso no sólo en el terreno que se dedica al desarrollo del mismo (con su correspondiente capacidad de carga), sino en la adopción de un conjunto de inversiones colaterales (Swanson, 1994). Estas medidas, así como la ampliación del terreno dedicado al recurso, desplaza la curva hacia fuera, permitiendo mayores tasas de crecimiento de este último. Por el contrario, cuando el recurso pierde su valor de uso directo, estas variables se mueven en sentido contrario, contrayendo la curva de crecimiento y haciendo más difícil una gestión ecológicamente sustentable.

\section{Investigación farmacéutica y biodiversidad}

Más complicado es el caso de la biodiversidad y la industria farmacéutica. Algunos países subdesarrollados, en efecto, poseen un activo que pueden tratar de rentabilizar ofreciendo su explotación a la industria farmacéutica y cobrando por ello. Se conseguiría así no sólo preservar el entorno sino también financiar el proceso de desarrollo. Sin embargo, es necesario poner en perspectiva las posibilidades existentes en este

GRAFICO 4

\section{Tasa de crecimiento de un recurso renovable}

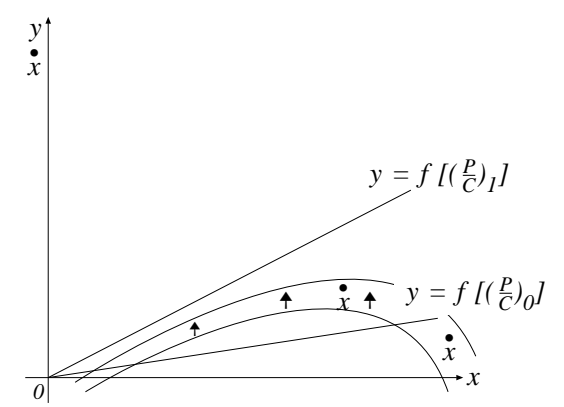

Fuente: Adaptado de Swanson (1994).

conclusión de que la reintroducción controlada de una serie de prácticas prohibidas (caza deportiva, caza por parte de la población local, utilización de la carne de elefante en las explotaciones de cocodrilos para comercializar su piel, etc.), elevaría notablemente la rentabilidad tanto económica (para el país) como financiera (para la población local) de los elefantes y, en definitiva, contribuiría en mayor medida a su preservación. La prohibición de comerciar con sus productos estaba reduciendo innecesariamente su valor económico al estrictamente derivado de la observación. 
campo, antes de echar las campanas al vuelo. Por un lado, estimaciones rigurosas sobre los pagos que podrían ofrecerse a los países depositarios de la biodiversidad por este concepto, teniendo en cuenta que se calculan como un porcentaje de las ganancias que la empresa farmacéutica deriva de la explotación comercial del producto finalmente obtenido, arrojan cifras realmente modestas, sobre las que difícilmente se podría apoyar la preservación de esta riqueza (Simpson, Sedjo y Reid, 1996). Por otro, conviene recordar que para poder llevar a cabo esta operación es necesario en primer lugar invertir en conservar la biodiversidad de un determinado entorno, algo que, dada su naturaleza de bien público, sólo puede hacer la administración. En general, las autoridades de estos países proporcionan una serie de servicios adicionales (identificación, clasificación en laboratorios y centros de investigación locales) por los que no cobran. Si a ello se añade el costo de oportunidad de las tierras dedicadas a la preservación de la biodiversidad, el "negocio" puede resultar ruinoso. Barbier y Aylward (1996) calcularon que el valor presente neto de los beneficios que por este concepto recibiría Costa Rica de la preservación de un determinado espacio natural durante un período de 40 años, alcanzaría la suma de 4.6 millones de dólares. Por su lado, el valor presente neto de los costos, incluido el de oportunidad de las tierras protegidas, sumaba 240 millones de dólares para el mismo período.

No es de extrañar, por lo tanto, la importancia del marco institucional en el que se cierra este tipo de acuerdos (aunque los cálculos de los autores citados no dejan mucho pie para la esperanza en este contexto), y la necesidad de coordinación entre los distintos países detentadores de la biodiversidad (y que son hasta cierto punto sustitutivos), para no competir entre ellos y perder de esta forma una parte importante de los beneficios de explotarla comercialmente. Conviene recordar, además, que el marco institucional en el que se manifiestan estas transacciones no reconoce a sus verdaderos dueños, los pueblos indígenas, la propiedad intelectual de una gran cantidad de medicinas y tratamientos que se han desarrollado a partir de su conocimiento de la naturaleza, y que han generado cuantiosos beneficios a la industria farmacéutica (AzquetaBernar, 1996).

En cualquier caso, y con la matización apuntada de la industria farmacéutica, esta rentabilización de algunos de los servicios de los recursos naturales y ambientales parece ser ciertamente positiva. No está de más señalar, sin embargo, un par de limitaciones obvias de esta venta de servicios ambientales con respecto al binomio pobreza-degradación ambiental. En primer lugar, la rentabilización de los servicios recreativos de determinados espacios naturales no tiene nada de objetable, pero deja fuera del circuito a todos aquellos entornos naturales que no tienen la consideración de "catedrales de la naturaleza", y que están particularmente amenazados; precisamente por ello han evolucionado en esa dirección las distintas figuras de protección de espacios naturales (López Ramón, 1996). En cuanto a la resolución del otro problema, el del desarrollo, la dificultad estriba en que estas catedrales, como todo, no parecen estar bien repartidas, y muchos países y regiones han recibido muy poco. Se trata, por tanto, de un esquema probablemente mejor que los anteriormente examinados, pero al que no se puede confiar por entero ni la solución del problema ambiental de la preservación global de espacios naturales ni el alivio del problema global de la pobreza.

\section{$\mathrm{V}$}

\section{Internalización de externalidades ambientales}

Una cuarta posibilidad, ciertamente interesante y que apenas comienza a materializarse, se plantea cuando se reconoce que algunos recursos naturales generan una serie de externalidades positivas, que repercuten en beneficio de todos. Uno de los casos más obvios es el papel que cumplen las grandes masas forestales al fijar el carbono atmosférico. La presencia de estas externalidades positivas introduce inmediatamente una tensión muy fuerte entre el interés común, por un lado, y el particular de quien, considerándose con derecho a disfrutar del activo, ve cómo se le pretende negar su aprovechamiento financiero en aras de algo que a él sólo muy tangencialmente le reporta algún beneficio. ${ }^{15}$

\footnotetext{
${ }^{15}$ Este es precisamente el motivo de que el análisis económico, en general, esté en contra de la patrimonialización de los recursos ambientales y naturales que generan una serie de externalidades positivas: cuanto más pequeño es el grupo en cuyo favor se reconoce la propiedad del recurso, mayor es la divergencia entre los beneficios financieros de su explotación (que se reparten entre po$\cos )$, y los costos ambientales de ella (que se reparten entre todos).
} 
El conflicto es antiguo: los países poseedores del bosque tropical contemplan cómo, en nombre de los intereses generales, quienes no tuvieron ningún cuidado en preservar los suyos tratan ahora de impedirles una explotación financieramente rentable de él, a lo que se añade el hecho de que los países ricos tampoco parecen dispuestos a ofrecer muchas vías alternativas de solución al problema del subdesarrollo (abriendo sus mercados, por ejemplo). Analicemos a este respecto dos posibilidades ciertamente significativas.

\section{Depósito de carbono}

Desde el punto de vista estrictamente económico, el anterior es un problema típico de generación de externalidades positivas, que no repercuten en beneficio del dueño del recurso. Una solución podría ser la de tratar de internalizar el beneficio proporcionado por estos servicios; de esta forma, el resto del mundo pagaría a los administradores de los bosques tropicales el valor de los servicios que éstos proporcionan al retener una cantidad de carbono que, de otra forma, una vez liberado agravaría el problema del calentamiento global de la atmósfera. Es lo que ocurriría, por ejemplo, si se procediera a la quema o tala de estos espacios para dedicarlos a la actividad agrícola y/o ganadera, como de hecho hicieron en su momento muchos países hoy desarrollados.

No resulta fácil computar el valor de este beneficio, pero una vía bastante utilizada es la de calcular el costo económico que supondría reducir las emisiones, en el origen, de una cantidad equivalente de carbono a través de la reconversión industrial, pongamos por caso, o de una modificación en los sistemas de transporte público. Esto permitiría obtener el precio de cuenta del recurso sobre la base de esta función ambiental. Es más, una vez aceptado el principio de la necesidad de remunerar estas funciones ambientales que cumplen determinados recursos naturales, la lógica inherente a tal principio llevaría a remunerar asimismo a los países poseedores de depósitos de combustibles fósiles (petróleo, carbón) por la no extracción de los mismos y su mantenimiento como depósitos de carbono (Goodland y Daly, 1996).

\section{Sumideros de carbono}

De lo anterior se desprende una segunda posibilidad que, tratada con cierto cuidado, también resulta de interés. En efecto, algunos países desarrollados (concretamente Canadá) están analizando la rentabilidad de forestar o reforestar tierras con el único propósito de secuestrar el carbono atmosférico; de esta forma se evitarían tener que reducir en el origen las emisiones en una cuantía equivalente, para cumplir con los compromisos ambientales que han contraído. En este sentido, Van Kooten, Binkley y Delcourt (1995) han estimado que el costo de fijar una tonelada métrica de carbono por esta vía para un país como Canadá o los Estados Unidos oscilaría entre los 6.64 y los 10.67 dólares, cifra que no se compara desfavorablemente con los 1.35 a 59.41 dólares que costaría hacerlo a través de otras vías; y ello sin contar con los beneficios adicionales que en otros aspectos supone la generación de una masa forestal. ${ }^{16}$ Además de esta contribución directa a la disminución del carbono atmosférico, secuestrándolo, los bosques y árboles, sobre todo urbanos, también contribuyen indirectamente a este fin, reduciendo el consumo de energía para ciertas actividades. En efecto, en países como los mencionados, una distribución adecuada de árboles alrededor de las viviendas puede llegar a reducir en 50\% la demanda de aire acondicionado y en 15\% la de calefacción (Sedjo, Wisniewski, Sample y Kinsman, 1995). Sería posible, entonces, llevar a cabo esta operación también en países en desarrollo, reforestando tierras marginales que incluso podrían servir de cinturón protector para otros espacios, y remunerarles por ello. El problema estriba en que, precisamente por la rentabilidad económica de esta operación, pudiera parecer atractivo transformar el bosque maduro primario en un sumidero de carbono, desplazando los árboles existentes por unos nuevos que, gestionados con este propósito, maximizaran la cantidad de carbono secuestrado. Una opción de esta naturaleza, sin embargo, no resistiría fácilmente un análisis costo-beneficio; al hacerlo se perdería no sólo un depósito ya existente de carbono, sino todos los servicios que el resto de las funciones ecológicas del bosque primario proporcionan y cuyo valor económico, a juzgar por los datos ofrecido en el excelente trabajo de Constanza, D'Arge y De Groot (1997), es considerablemente alto y arroja un precio por hectárea de

\footnotetext{
${ }^{16}$ Con base en estas cifras, los autores llevan a cabo un análisis de lo que sería una política óptima de subsidios tanto a la reforestación como a la utilización posterior de la madera, de forma que mantenga secuestrado el carbono: el $40 \%$ de la madera utilizada para la construcción permanece después de 50 años, mientras que en la utilizada para la fabricación de papel la cifra es apenas de 3\% (Sedjo, Wisniewski, Sample y Kinsman, 1995). Llegaría a estar justificada, por este concepto, una subvención al enterramiento sin más de la madera, como mecanismo de asegurar un mínimo retorno del carbono a la atmósfera.
} 
bosque tropical bastante superior al que supondría la explotación financiera del terreno como fuente de madera, de pastos, o de cualquier otra opción de mercado.

En términos generales, y a título meramente ilustrativo, Fearnside (1997) calculó que los servicios ambientales de la selva amazónica alcanzarían los 7 mil millones de dólares anuales por concepto de mantenimiento de la biodiversidad; 24 mil millones como depósito de carbono y 7 mil millones más por su papel en el ciclo hídrico. Las dos primeras son externalidades que benefician ciertamente a toda la humanidad. La primera, además, en opinión del autor no debería ser descontada con el paso del tiempo, mientras que la segunda sí para reflejar el distinto valor de fijar el carbono en función de cuándo se produce este hecho. La tercera (regulación del ciclo hídrico) tiene un carácter más local, ya que lo que se contempla aquí es el papel de la selva amazónica como generadora de lluvias en la propia zona, y el impacto de estas lluvias sobre la productividad de las tierras agrícolas. En cualquier caso, y como el propio autor reconoce, estos cálculos a vuela pluma no incluyen muchos otros aspectos positivos de la selva amazónica, pero no dejan de ser una buena aproximación tanto a las magnitudes envueltas como al camino que se ha de seguir. ${ }^{17} \mathrm{Sin}$ embargo, al igual que en el caso de la explotación de los servicios recreativos de los espacios naturales, no se puede perder de vista que si bien el valor económico del bosque así computado probablemente sea muy superior al de cualquier otra opción, financieramente el cambio puede resultar perjudicial para la población que utilizaba el recurso, y que ahora puede verse privada de acceso a él. Shyamsundar y Kramer (1996), en un interesante análisis en el que combinan el método basado en la función de producción con el de valoración contingente (utilizando para ello, en uno de los

\footnotetext{
${ }^{17}$ Debido a que algunos de estos beneficios ambientales están sujetos tanto a la incertidumbre sobre el futuro como a la irreversibilidad que supondría, en su caso, permitir en ellos actividades financieramente rentables, pero incompatibles con su mantenimiento en el largo plazo, se complica sustancialmente el proceso de toma de decisiones al respecto. Albers, Fisher y Hanemann (1996) estudian el caso del Parque Nacional Khao Yai en Tailandia, modelizando el problema de un gestor que tiene ante sí tres alternativas excluyentes: preservación del entorno, desarrollo semisostenible de él y desarrollo no sostenible. Teniendo en cuenta en un modelo dinámico las posibles secuencias abordables e intentando maximizar el valor presente neto de la mejor de ellas, en el estudio se muestra que la estrategia convencional de maximización de la función objetivo (open loop) es inferior a la que incorpora esta incertidumbre con respecto al futuro (closed loop) que se traduce en una mayor preservación del entorno.
}

escasos ejemplos existentes en la literatura, el formato de la compensación exigida), calcularon la pérdida de bienestar que para los habitantes de la zona supuso la protección del Parque Natural de Mantadia, en Madagascar. El resultado indica que el perjuicio está lejos de ser desdeñable: su valor en este caso prácticamente igualaba el valor comercial de la cosecha de arroz.

\section{Canje de deuda por naturaleza}

En la línea anterior podrían enmarcarse los esquemas de canje de deuda por naturaleza que florecieron hace algunos años entre distintas organizaciones no gubernamentales (ONG) y algunos países en desarrollo. El sistema es bien sencillo y conocido: consiste simplemente en comprar deuda pública externa en el mercado secundario, con un fuerte descuento, y cambiársela al país emisor por algún compromiso ambiental: creación de nuevas reservas naturales, ampliación y/o mejora de las existentes u otras acciones. ${ }^{18}$ Dejando de lado cuestiones siempre vidriosas de soberanía, el problema con estos esquemas, además de su carácter un tanto voluntarista y no organizado, es que pueden traducirse en un aumento del precio de la deuda en el mercado secundario (debido al incremento de la demanda). Este aumento no favorece al país emisor sino al acreedor (que ve cómo se revaloriza un activo que consideraba perdido), ni facilita sucesivas operaciones en la misma dirección, como parece que ocurrió. Sería preferible, por lo tanto, formalizar el pago de estas externalidades ambientales positivas, tanto con respecto al marco institucional, estableciendo algún organismo o agencia supranacional encargada de ello (lo que re-

\footnotetext{
${ }^{18}$ Entre los más significativos podrían destacarse: la compra de 650000 dólares nominales de deuda externa boliviana por la Fundación Frank Weeden, a cambio de aumentar la protección de un área natural del Beni; el canje de un millón de dólares de deuda externa ecuatoriana que el Wild World Fund (WWF) adquirió en el mercado secundario (a un $30 \%$ de su valor nominal), a cambio de inversiones en educación ambiental, en una primera instancia, y de otros cinco millones y medio de valor nominal ( $12 \%$ del valor de mercado) algunos años más tarde a cambio de inversiones de conservación en la Amazonia ecuatoriana y en las islas Galápagos; la compra por parte de la ong The Nature Conservancy de 2.2 millones de deuda externa brasileña a un banco privado por 850000 dólares, y su canje con el gobierno por deuda interna (seis pagos anuales de 132000 dólares en moneda local, al 6\% de interés) utilizada para gestionar por parte de una ONG local (Fundação ProNaturaleza) el Parque Grande Sertão Veredas; o el canje, también a cargo del wwF, de dos millones de dólares de deuda filipina a cambio de bonos nacionales utilizados para la creación de dos parques naturales (Pearce y Warford, 1993).
} 
duciría los siempre espinosos problemas relativos a la soberanía), como al marco estrictamente económico, determinando con algún criterio las corrientes de pago debidas.

Volviendo al doble tema que nos ocupa, esta internalización y la rentabilización consiguiente de algunas externalidades ambientales parecerían ser un complemento ideal para lo analizado en el apartado anterior, desde el punto de vista de la conservación y protección de la naturaleza, tanto más cuanto mayor sea el conjunto de servicios ambientales reconocidamente desempeñados por estos recursos en beneficio de toda la humanidad. No parece que se pueda decir lo mismo, desgraciadamente, de su posible contribución a solucionar el problema global de la pobreza; sencillamente no todos los países o regiones pobres han tenido la suerte de contar con estos recursos y poder preservarlos. Y no se encuentran entre ellos los más desfavorecidos y necesitados. El cuadro 1 muestra, por ejemplo, cómo están repartidas las principales masas boscosas en la actualidad, presentando una situación que bien pudiera caracterizarse como de oligopolio. El problema es que este oligopolio no sólo resulta poco adecuado, como decimos, para resolver los problemas globales de la pobreza, sino que puede incluso dificultar la solución del propio problema ambiental. En efecto, Stähler (1996) muestra, utilizando la teoría del control óptimo, que cuando los países desarrollados tienen disposición a pagar cada vez más por el mante- nimiento de un recurso a medida que éste se hace más escaso, y los países poseedores del recurso son pocos y actúan estratégicamente, la conducta óptima de estos últimos puede conducir a un menor nivel de equilibrio del acervo del bien ambiental que si no hubiese un pago por su preservación. En este sentido, la financiación de proyectos específicos de conservación que impliquen algún grado de control sobre el recurso podría ser una alternativa más apropiada que el pago indiscriminado por su conservación, aunque menos aceptable desde el punto de vista de la soberanía.

CUADRO 1

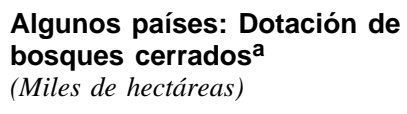

\begin{tabular}{lrr}
\hline Bolivia & 44010 & \\
Brasil & 357480 & \\
Colombia & 46400 & \\
México & 46250 & \\
Venezuela & 31870 & \\
Zaire & 105750 & \\
Indonesia & 113395 & \\
Perú & 69680 & \\
& & \\
Total 8 países & 815335 & $(56.75 \%)$ \\
Total mundial & 1436492 & $(100 \%)$ \\
\hline
\end{tabular}

Fuente: Stähler (1996).

a Se suprimió el dato relativo a la India (36 450 miles de hectáreas), por considerar que distorsionaba la conclusión global del cuadro.

\section{VI}

\section{El acceso a recursos ambientales globales comunes: un mercado para los derechos de contaminación}

Puede parecer contradictorio plantear la necesidad de una defensa más activa del medio ambiente y, al mismo tiempo, introducir en el debate nada menos que los "derechos a contaminar". Pero probablemente no lo sea.

En efecto, como se expone en la sección II de este artículo, el grado de contaminación óptimo no es cero: eso supondría renunciar a la producción y consumo de casi todos los bienes y servicios en los que se basa la vida organizada. El ser humano, por lo tanto, parece dispuesto a utilizar en cierta medida la biosfera para satisfacer sus propias necesidades ${ }^{19}$ Esto implica, naturalmente, aprovecharse de sus funciones positivas aun respetando sus límites. Entre estas funciones, vale la pena destacar la capacidad de la biosfera de asimilar los desechos generados en el proceso de producción y consumo; como muy bien recuerda la ecología, éste es un sistema cerrado desde el punto de vista de

\footnotetext{
${ }^{19}$ Sobre el fascinante problema de si esto es éticamente defendible o no, el lector interesado puede consultar los trabajos incluidos en Elliot (1995).
} 
la materia, en el que el ser humano toma de la biosfera una serie de elementos para su transformación, uso y disfrute, por un lado, y devuelve desechos y entropía, por otro.

Ahora bien, la capacidad de absorción de la biosfera con respecto a estos desechos es limitada. Hasta ahora, y dado su carácter de un recurso común de libre acceso, cada cual se deshacía de los residuos, utilizando para ello el entorno (atmósfera, agua o suelos) conforme lo necesitaba. La aplicación de la "ley de captura" ha traído los problemas que hoy sufrimos, y la necesidad de un replanteamiento total de la situación. Replanteamiento que se traduce en el establecimiento de límites con respecto a lo que se puede devolver al medio ambiente en forma de desechos y basuras con respecto, por ejemplo, a lo que se puede emitir a la atmósfera sin poner en peligro la viabilidad del sistema. En este sentido, y ya que se trata de un recurso escaso, vale la pena preguntarse cómo debería repartirse el derecho a disfrutar de este servicio ambiental: el derecho a emitir $\mathrm{CO}_{2}$ a la atmósfera, por poner como ejemplo un problema ya abordado. Este, y no otro, es el "derecho a contaminar" que se mencionaba más arriba: el derecho a disfrutar de los servicios de la biosfera como depósito de residuos, dentro de los límites que marca la capacidad de absorción del sistema. $^{20}$

El problema que se plantea, pues, es el de encontrar un mecanismo a la vez justo y eficiente para repartir estos permisos de emisión.

Una alternativa que ha sido objeto de numerosos análisis, tanto desde un punto de vista teórico como de simulación de sus resultados, es la de "comprar" la participación de los países subdesarrollados en esquemas de reducción de la contaminación global. Es el caso, por ejemplo, de los trabajos de Bohm y Larsen (1994) y Larsen y Shah (1994) respecto del $\mathrm{CO}_{2}$, y Klaasen, Forsund y Amann (1994) respecto del $\mathrm{SO}_{2}$. Veamos uno de ellos con algo más de detalle.

El trabajo mencionado de Larsen y Shah (1994), cuyos principales resultados se resumen en el cuadro 2, es bien ilustrativo al respecto. Los autores examinan la posibilidad de establecer un régimen de permisos comercializables de emisión de dióxido de carbono

\footnotetext{
${ }^{20}$ De hecho, el problema no se planteará en términos de contaminantes individuales (como el $\mathrm{CO}_{2}$ ), sino de objetivos deseables, y de la contribución de conjuntos de variables a su consecución (Schaltegger y Thomas, 1996). Para el análisis que deseamos abordar, sin embargo, esta matización es irrelevante.
}

$\left(\mathrm{CO}_{2}\right)$, con miras a estabilizar las emisiones para el año 2000 en los niveles de $1987 .{ }^{21} \mathrm{El}$ problema es que para que un acuerdo de esta naturaleza tenga posibilidades de ser efectivo no se puede dejar al margen a los países no desarrollados (países no OCDE, para simplificar) que son responsables del $43 \%$ de las emisiones, según datos de 1987. Ahora bien, los incentivos que pueden tener estos países para participar en un esquema de reducción de emisiones son más bien limitados. Tomando en consideración los límites que se plantean como objetivo, y los costos marginales de reducir las emisiones de $\mathrm{CO}_{2}$ (utilizando para ello la extendida función propuesta por Nordhaus), ${ }^{22}$ Larsen y Shah llegan a la conclusión de que el precio unitario de un permiso de emisión sería de 58 dólares por tonelada. A partir de este dato, puede construirse la función de costo/beneficio que le supondría a cada país participar en el esquema, dependiendo de cómo se adjudiquen los permisos, y teniendo en cuenta que, en equilibrio, cada país reducirá sus emisiones hasta que el costo marginal de hacerlo sea igual al precio del permiso.

A partir de aquí se analizan distintas modalidades de reparto de estos "derechos de emisión", teniendo siempre presente que sólo si un país percibe un valor monetario, en términos de permisos concedidos, que supere los beneficios a los que renuncia por su participación en el acuerdo, tendrá incentivos para participar. Veamos cuatro de estos posibles esquemas de asignación: ${ }^{23}$

i) Asignación de derechos en función de la población, de forma que la cuantía de permisos per cápita sea igual en todos los países (0.915 toneladas), como sugirieron en su momento dos economistas indios, Agarwal y Narain (Martínez-Alier, 1992), y han reco-

\footnotetext{
${ }^{21}$ En la reunión cumbre sobre el cambio climático celebrada en la ciudad de Kioto se manejaron objetivos algo diferentes; lo fundamental, sin embargo, es el marco teórico que proporciona este trabajo y que sería fácilmente adaptable a cambios de esta naturaleza, sin que los resultados esenciales se vieran modificados.

${ }^{22}$ La función de costos mencionada tiene la siguiente expresión: $R=1-e^{-0,0054 M C}$

en la que $R$ es el porcentaje de reducción de las emisiones de $\mathrm{CO}_{2}$ y $M C$ es el correspondiente costo marginal de alcanzarlo (dólares por tonelada).

${ }^{23}$ El artículo aborda dos cuestiones adicionales. La primera hace referencia al problema planteado por los "polizones" (free-riders), considerando que al tener en cuenta la asignación como una variable más se puede reducir la probabilidad de que se presente este fenómeno entre los propios países de la oCDE, aunque reconociendo que tal posibilidad no desaparece del todo. La segunda se refiere a la función de costos marginales utilizada (que ha sido muy debatida), analizando la solidez de los resultados obtenidos con distintas funciones.
} 
CUADRO 2

Mundo: Costos (-) y beneficios (+) de los distintos esquemas de reparto de los derechos de emisión de $\mathrm{CO}_{2}$ (Como porcentaje del PIB)

\begin{tabular}{|c|c|c|c|c|c|c|c|}
\hline \multirow[t]{2}{*}{ Países } & \multirow[t]{2}{*}{$\begin{array}{l}\text { PIB per } \\
\text { cápita }^{\mathrm{a}}\end{array}$} & \multirow{2}{*}{$\begin{array}{c}\text { Emisiones } \\
\text { sobre PIB } \\
\text { (kg/dólar) }^{\mathrm{a}}\end{array}$} & \multirow{2}{*}{$\begin{array}{c}\text { Emisiones } \\
\text { per cápita } \\
(\mathrm{kg})^{\mathrm{a}}\end{array}$} & \multicolumn{4}{|c|}{$\begin{array}{c}\text { Alternativas de reparto: } \\
\text { ventajas netas como \% del PIB }\end{array}$} \\
\hline & & & & A & $\mathrm{B}$ & $\mathrm{C}$ & $\mathrm{D}$ \\
\hline Bangladesh & 166 & 0.18 & 30 & 25.38 & -0.16 & 0.23 & \\
\hline Nigeria & 229 & 0.37 & 84 & 26.63 & -0.93 & 0.35 & \\
\hline China & 286 & 1.87 & 533 & 1.92 & -6.06 & 1.15 & \\
\hline India & 322 & 0.57 & 182 & 7.92 & -1.73 & 0.47 & \\
\hline Pakistán & 325 & 0.39 & 128 & 11.11 & -0.68 & 0.31 & \\
\hline Indonesia & 443 & 0.35 & 153 & 6.41 & -0.14 & 0.23 & \\
\hline Zimbabwe & 598 & 0.77 & 463 & 5.58 & -2.04 & 0.52 & \\
\hline Egipto & 709 & 0.54 & 380 & 1.98 & -1.75 & 0.48 & \\
\hline Rep. Pop. Dem. de Corea & 889 & 2.06 & 1834 & -3.58 & -9.10 & 1.62 & \\
\hline México & 1715 & 0.55 & 943 & -0.10 & -1.46 & 0.43 & \\
\hline Brasil & 2145 & 0.17 & 356 & 0.97 & 0.42 & 0.14 & \\
\hline Sudáfrica & 2493 & 0.92 & 2292 & -2.72 & -3.63 & 0.77 & \\
\hline Venezuela & 2629 & 0.49 & 1276 & -0.39 & -1.30 & 0.41 & \\
\hline República de Corea & 3121 & 0.34 & 1067 & -0.64 & -0.13 & 0.22 & \\
\hline Polonia & 1700 & 1.96 & 3338 & -5.83 & -7.39 & 1.36 & \\
\hline Yugoslavia & 2700 & 0.52 & 1403 & -0.42 & -0.99 & 0.36 & \\
\hline U.R.S.S. & 2900 & 1.23 & 3578 & -3.79 & -4.16 & 0.85 & \\
\hline Checoslovaquia & 2400 & 1.71 & 4110 & -5.56 & -6.28 & 1.18 & \\
\hline Suiza & 26115 & 0.06 & 1580 & -0.12 & 1.04 & -0.15 & -0.30 \\
\hline Islandia & 21873 & 0.09 & 1955 & -0.22 & 0.91 & -0.22 & -0.44 \\
\hline Noruega & 19963 & 0.10 & 2048 & -0.26 & 0.85 & -0.26 & -0.51 \\
\hline Dinamarca & 19830 & 0.16 & 3238 & -0.54 & 0.58 & -0.41 & -0.81 \\
\hline Suecia & 19257 & 0.09 & 1812 & -0.21 & 0.89 & -0.24 & -0.47 \\
\hline Alemania & 16754 & 0.20 & 3427 & -0.69 & 0.40 & -0.51 & -1.02 \\
\hline Finlandia & 18070 & 0.16 & 2925 & -0.51 & 0.59 & -0.41 & -0.80 \\
\hline Luxemburgo & 16331 & 0.36 & 5930 & -1.38 & -0.30 & -0.91 & -1.81 \\
\hline Francia & 15913 & 0.10 & 1636 & -0.22 & 0.85 & -0.26 & -0.51 \\
\hline Austria & 15441 & 0.11 & 1717 & -0.25 & 0.82 & -0.28 & -0.55 \\
\hline Países Bajos & 14521 & 0.17 & 2428 & -0.57 & 0.57 & -0.42 & -0.83 \\
\hline Bélgica & 14457 & 0.18 & 2.637 & -0.55 & 0.50 & -0.46 & -0.91 \\
\hline Italia & 13176 & 0.13 & 1691 & -0.29 & 0.74 & -0.32 & -0.64 \\
\hline Reino Unido & 12024 & 0.23 & 2707 & -0.69 & 0.31 & -0.56 & -1.12 \\
\hline Irlanda & 8353 & 0.25 & 2170 & -0.68 & 0.18 & -0.64 & -1.26 \\
\hline España & 7452 & 0.15 & 1123 & -0.18 & 0.64 & -0.38 & -0.75 \\
\hline Grecia & 4619 & 0.31 & 1437 & -0.58 & -0.07 & -0.78 & -1.55 \\
\hline Portugal & 3612 & 0.21 & 758 & 0.09 & 0.38 & -0.53 & -1.04 \\
\hline Turquía & 1293 & 0.50 & 649 & 1.36 & -0.92 & -1.26 & -2.50 \\
\hline Japón & 19437 & 0.10 & 1942 & -0.25 & 0.87 & -0.25 & -0.50 \\
\hline Estados Unidos & 18434 & 0.28 & 5112 & -1.01 & 0.08 & -0.70 & -1.38 \\
\hline Canadá & 16056 & 0.26 & 4221 & -0.92 & 0.14 & -0.66 & -1.31 \\
\hline Australia & 11364 & 0.35 & 3932 & -1.16 & -0.23 & -0.87 & -1.72 \\
\hline Nueva Zelanda & 10749 & 0.16 & 1709 & -0.33 & 0.60 & -0.40 & -0.79 \\
\hline OCDE & & 0.20 & 3015 & -0.62 & 0.43 & -0.50 & -0.99 \\
\hline Resto del mundo & & 0.55 & 639 & 0.80 & -1.47 & 0.43 & \\
\hline Mundo & & 0.34 & 1112 & -0.24 & -0.24 & -0.24 & \\
\hline
\end{tabular}

Fuente: Larsen y Shah (1994).

a Datos de 1987. 
gido personas tan respetadas como Herman Daly (Goodland y Daly, 1992). Desde un punto de vista puramente lógico, da la impresión de que todo ser humano debería tener el mismo derecho a utilizar la atmósfera (respetando los límites mencionados) y, por lo tanto, todas las personas deberían tener el mismo derecho a emitir. Podría matizarse la afirmación anterior, si se considera oportuno, para tener en cuenta la responsabilidad actual e histórica de las distintas sociedades en la creación del problema (en el acervo de desechos ya emitidos) y en su solución (manteniendo ecosistemas que ayudan a reducirlos). Pero en cualquier caso, el principio subyacente no variaría: el reconocimiento de un mismo derecho al disfrute de los servicios comunes de la naturaleza, que no debería estar mediatizado por consideraciones de raza, riqueza o cualquier otra variable que a alguien se le pudiera ocurrir. ${ }^{24}$ Es probable que, como se ha señalado repetidamente, los pobres vendan barato, pero barato o caro, los cálculos que se han hecho con respecto a lo que un esquema de este tipo supondría para los países subdesarrollados deja poco lugar a dudas: como puede comprobarse en el cuadro 2 (columna A) que muestra para cada país las ganancias de participar en el acuerdo -medidas por el incremento del PIB en el año 2000 - , los países pobres se verían notablemente beneficiados. La factura la pagarían los países desarrollados, que recibirían permiso para emitir un 25\% de sus emisiones proyectadas, y la mayor parte de los países de ingresos medios y las economías emergentes.

ii) Asignación de derechos en función del PIB proyectado de cada país para el año 2000 con respecto al PIB mundial ( $0.23 \mathrm{~kg}$ por dólar). Con este sistema pierden la mayor parte de los países de ingresos bajos y medianos, así como las economías emergentes (columna B), por lo que no estarían dispuestos a participar en un esfuerzo conjunto de reducción de emisiones, que favorecería a los países desarrollados.

iii) Asignación de derechos de manera que los países subdesarrollados cubran sus emisiones proyec-

\footnotetext{
${ }^{24}$ No conviene olvidar, sin embargo, el papel de la política con respecto al crecimiento de la población: un esquema como el propuesto privilegiaría la adopción de políticas natalistas, discriminando en contra de aquellos países que están procurando o han procurado contener el crecimiento poblacional, lo que puede resultar éticamente inaceptable.
}

tadas para el año 2000. De esta forma, en principio, no tendrían ninguna objeción. El resto de las emisiones permitidas hasta llegar al tope propuesto se repartiría entre los países de la OCDE en función, por ejemplo, de sus emisiones pasadas o de cualquier otro criterio que se considere aceptable. Los resultados de este sistema (columna C) indican que muchos países subdesarrollados ganarían participando en un acuerdo de esta naturaleza. La razón es bien sencilla: el valor económico de los permisos que podrían vender si no los utilizan, superaría el costo de adoptar tecnologías menos contaminantes.

iv) Reducción unilateral de las emisiones por parte de los países de la OCDE. Bajo este sistema (columna D), los países desarrollados darían por supuesto que los demás no van a tomar medida alguna, y reducirían unilateralmente sus emisiones en consecuencia: exactamente igual que en el caso anterior. La diferencia estriba en que el mercado de permisos de emisión se circunscribiría al ámbito de los países desarrollados (participantes), lo que impediría explotar las ganancias de eficiencia que supone el hecho de que los costos de reducir las emisiones en los países subdesarrollados, o de no utilizar los permisos que se les asignarían, fuesen más bajos. Como resultado, el precio de cada permiso pasaría de los 58 dólares señalados por Larsen y Shah (1994) a 181.

En definitiva, si los permisos de emisión se reparten de acuerdo con la primera o la tercera de las opciones contempladas, éste parece ser un esquema mucho más prometedor que los anteriores en el doble aspecto que venimos analizando. Por lo que toca al problema ambiental, en tanto, trata de alcanzar algunos objetivos sociales que permitan la sustentabilidad global; además, resulta ser un sistema compatible con incentivos para adoptar tecnologías más limpias. Por lo que respecta al problema de la pobreza, tiene la gran ventaja de que, al tratarse de recursos globales y comunes, su disfrute no depende de la arbitrariedad con que la naturaleza repartió sus "regalos". Esto es algo que parece más aceptable desde el punto de vista de la equidad. ${ }^{25}$

\footnotetext{
${ }^{25}$ Como se ha señalado insistentemente, para evitar un agravamiento de los problemas de la pobreza es fundamental que las compensaciones así recibidas no vayan a parar a manos de quien no lo necesita. En este sentido, se ha recomendado materializar estas compensaciones en una reducción de las cargas de la deuda externa, lo que permitiría suavizar en gran medida los programas de ajuste y los recortes presupuestarios que les acompañan, que de otra forma serían necesarios (Rotillon y Tazdaït, 1996).
} 


\section{VII}

\section{Conclusión}

Se han analizado en este trabajo las posibilidades que ofrece la dotación ambiental y de recursos naturales de los países y regiones subdesarrollados para aliviar el problema de la pobreza, a través de la explotación de las ventajas comparativas derivadas de esa dotación, en el marco del comercio internacional y sin generar una mayor degradación ambiental sino, por el contrario, garantizando la sustentabilidad del sistema.

Cinco fueron los posibles esquemas estudiados, en función de su contribución a resolver tanto los problemas de la pobreza como los del deterioro ambiental:

i) El dumping ecológico, apoyado en una aparente mayor disponibilidad a aceptar la contaminación por parte de los más desfavorecidos. Se le rechazó desde ambas perspectivas, como potencialmente nocivo para el medio ambiente y como éticamente injustificable. Su aparente racionalidad reposaba en dos premisas inaceptables: la mercantilización de la vida humana y una contabilidad incompleta de sus verdaderos costos sociales.

ii) La explotación de bienes que hacen uso intensivo de los recursos naturales, tanto renovables como no renovables, que tienen un precio de mercado. Al respecto se destacaron los límites establecidos por la sustentabilidad de la explotación en el primer caso, y la equidad intergeneracional en el segundo. Se hizo hincapié asimismo en que, en lo que hace a la solución del problema ambiental, esta rentabilización de los recursos naturales sólo permite preservar aquellos que prometen un rendimiento financiero superior a la tasa de interés del mercado, ya que en el proceso de toma de decisiones no se computan las externalidades ambientales positivas generadas por el recurso.

iii) La explotación financiera de determinados servicios de los espacios naturales. Se les miró como focos de un determinado tipo de turismo comprometido con el medio ambiente, que permitiría obtener un rendimiento económico de las llamadas "catedrales de la naturaleza", siempre que fueran gestionadas adecuadamente, y como materia prima para la investigación, sobre todo de la industria farmacéutica. El doble problema que presentan los dos casos analizados en este epígrafe es que, desde el punto de vista ambiental, no resuelven la situación de todos aquellos activos ambientales que generan externalidades positivas muy importantes (en algunos casos, esenciales) pero que no tienen un valor apropiable. Desde la perspectiva del problema de la pobreza, la solución que ofrecen está en función de cómo ha tenido a bien la naturaleza repartir sus dones.

iv) El cálculo del valor económico generado por las externalidades ambientales de distintos activos y ecosistemas, para proceder al pago correspondiente en favor de sus administradores. Este es un esquema mucho más potente para dar solución al problema ambiental, ya que valoriza todos los activos y todas sus funciones ambientales con independencia de que, gracias a la posibilidad de exclusión, se pueda cobrar un precio por sus servicios. Desgraciadamente, frente al problema de la pobreza choca con la misma limitación que el esquema anterior.

v) Y, por último, el esquema que en nuestra opinión resulta más prometedor para resolver los dos problemas planteados: la comercialización de los derechos a utilizar los recursos ambientales comunes y, en concreto, la capacidad de la atmósfera (y la biosfera en general) de absorber desechos. Una gestión supranacional del tema de las emisiones a la atmósfera, por ejemplo, no sólo permitiría resolver un problema ambiental muy grave, sino que con el esquema planteado pondría a disposición de los países y regiones más desfavorecidos recursos financieros muy importantes, con casi total independencia de la suerte que hayan tenido en el reparto de los dones de la naturaleza.

El análisis anterior valoriza económicamente las funciones ambientales de los recursos naturales y los ecosistemas, poniéndoles un precio para que se actúe en consecuencia. Esto puede resultar inaceptable para quienes rechazan la mercantilización del medio ambiente, considerando que en sus relaciones con la biosfera el ser humano no debería reducir ésta a la calidad de mercancía (Anderson, 1993, cap. 9). Sin ocultar nuestra simpatía por este tipo de planteamientos, conviene recordar sin embargo que lo que se busca es que quienes lo necesitan rentabilicen las funciones ecológicas de los distintos ecosistemas para hacer más eficiente su salvaguardia, compensando a quienes tendrían que renunciar a su explotación comercial. En este sentido, las decisiones sobre su preservación no se dejan en manos del mercado y su disfrute obviamente es compartido, características ambas que contradicen su 
pretendido carácter de mercancía. Como es natural, aquellos esquemas menos prometedores en ambos campos son los que ya están en marcha. Los dos últimos analizados, que requieren no sólo de un marco institucional supranacional sino del sacrificio de los países más adelantados, encuentran muchas más dificultades. Sin embargo, tanto desde el punto de vista de la eficiencia como desde el punto de vista de la equidad, constituyen un camino mucho más promisorio en ambos sentidos: desarrollo y sustentabilidad.

\section{Bibliografía}

Albers, J., A. C. Fisher y W. M. Hanemann (1996): Valuation and management of tropical forests: Implications of uncertainty and irreversibility, Environmental and Resource Economics, vol. 8, $\mathrm{N}^{\circ}$ 1, Dordrecht, Países Bajos, Kluwer Academic Publishers.

Anderson, E. (1993): Value in Ethics and Economics, Cambridge, Massachusetts, Harvard University Press.

Anderson, K. (1996): Environmental standards and international trade, Proceedings of the World Bank Annual Conference on Development Economics, Washington D.C., Banco Mundial.

Azqueta, D. (1992): Social project appraisal and environmental impact assessment, Development Policy Review, vol. 10, $\mathrm{N}^{\circ} 3$, Londres, Overseas Development Institute.

(1994): Valoración económica de la calidad ambiental, Madrid, McGraw-Hill.

Azqueta, D. y L. Pérez (1996): Gestión de espacios naturales: la demanda de servicios recreativos, Madrid, McGraw Hill.

Azqueta-Bernar, D. (1996): El conocimiento indígena. Ecología política, vol. 11, Madrid, FUHEM/ICARIA.

Barbier, E. B. y B. A. Aylward (1996): Capturing the pharmaceutical value of biodiversity in a developing country, Environmental and Resource Economics, vol. 8, $\mathrm{N}^{\circ}$ 2, Dordrecht, Países Bajos, Kluwer Academic Publishers.

Barnes, J.I. (1996): Changes in the economic use value of elephants in Bostwana: The effect of international trade prohibition, Ecological Economics, vol. 18, ํㅜ 3, Amsterdam, Países Bajos, Elsevier Science B.V.

Berck, P. y M. Roberts (1996): Natural resource prices: Will they ever turn up? Journal of Environmental Economics and Management, vol. 31, $\mathrm{N}^{\circ} 1$, Nueva York, Academic Press.

Bohm, P. y B. Larsen (1994): Fairness in a tradeable-permit treaty for carbon emissions reductions in Europe and the former Soviet Union, Environmental and Resource Economics, vol. 4, $\mathrm{N}^{\circ}$ 3, Dordrecht, Países Bajos, Kluwer Academic Publishers.

Burton, P.S. (1996): Land use externalities: Mechanism design for the allocation of environmental resources, Journal of Environmental Economics and Management, 30, pp. 174-185, Nueva York, Academic Press.

Chichilnisky, G. (1994): North-south trade and global environment, The American Economic Review, vol. 84, N 4, Washington, D.C., American Economic Association.

Comunidad Europea (1995): ExternE: Externalities of energy, Directorate-General XII, Science Research and Development, Luxemburgo.

Constanza, R., R. D'Arge, R. de Groot (1997): The value of the world's ecosystem services and natural capital, Nature, vol. 387, Washington, D.C., Mc Millan Publishers, 15 de mayo.

Copeland, B. R. y M. S. Taylor (1995a): Trade and transboundary pollution, The American Economic Review, vol. 85, $\mathrm{N}^{\circ} 4$, Washington, D.C., American Economic Association.

(1995b): Trade and the environment: A partial synthesis, American Journal of Agricultural Economics, vol.77, $\mathrm{N}^{\circ} 3$, Ames, Iowa, American Agriculture Economics Association.
Dixon, J. A., L. F. Scura y T. van't Hof (1995): Ecology and microeconomics as joint products: The Bonaire Marine Park in the Caribbean, en C.A. Perrings y otros, Biodiversity Conservation, Dordrecht, Países Bajos, Kluwer Academic Publishers.

Elliot, R. (1995): Environmental Ethics, Oxford, Reino Unido, Oxford University Press.

Fearnside, P.M. (1997): Environmental services as a strategy for sustainable development in rural Amazonia, Ecological Economics, vol. 20, $\mathrm{N}^{\circ}$ 1, Amsterdam, Países Bajos, Elsevier Science B.V.

Gómez, C. M. (1994): Desarrollo sostenible y gestión eficiente de los recursos naturales, D. Azqueta y A. Ferreiro (eds.), Análisis económico y gestión de recursos naturales, Madrid, Alianza Editorial.

Goodland, R. y H. H. Daly (1992): Three steps towards global environmental sustainability, Development Journal of the Society for International Development, $\mathrm{N}^{\circ} 2$, Oxford, Reino Unido, Basil Blackwell.

(1996): If tropical log export bans are so perverse, why are there so many?, Ecological Economics, vol. 18, № 3 , Amsterdam, Países Bajos, Elsevier Science B.V.

Goodstein, E. S. (1995): Economics and the Environment, Englewood Cliffs, New Jersey, Prentice Hall.

Gottfried, R. R., C. D. Brockett y W.C. Davis (1994): Models of sustainable development and forest resource management in Costa Rica, Ecological Economics, vol. 9, ํㅜㄹ, Amsterdam, Países Bajos, Elsevier Science B.V.

Grey, F. (1995): Assessing Economic Benefits of Protected Areas, Melbourne, Economist at Large and Associates para la UIMC.

Grossman, G. M. y A.B. Krueger (1995): Economic growth and the environment, Quarterly Journal of Economics, vol. CX, $\mathrm{N}^{\circ} 2$, Cambridge, Massachusetts, Harvard University.

Klaasen, G. A., F. R. Forsund y M. Amann (1994): Emission trading in Europe with an exchange, Environmental and Resource Economics, vol. 4, № 4, Dordrecht, Países Bajos, Kluwer Academic Publishers.

Krugman, P. R. y M. Obstfeld (1995): Economía internacional: teoría y política, Madrid, McGraw-Hill.

Larsen, B. y A. Shah (1994): Global tradeable carbon permits, participation incentives, and transfers, Oxford Economic Papers, vol. 46, special issue, Londres, Oxford University Press.

Lee, J.R. (1996): Basic attributes of trade and environment: What do the numbers tell us?, Ecological Economics, vol. 19, № 33 , Amsterdam, Países Bajos, Elsevier Science B.V.

Lockwood, M. (1997): Integrated value theory for natural areas, Ecological Economics, vol. 20, $\mathrm{N}^{\circ}$ 1, Amsterdam, Países Bajos, Elsevier Science B.V.

López Ramón, F. (1996): Fuentes del régimen jurídico de los espacios naturales protegidos, D. Azqueta y L. Pérez, Gestión de espacios naturales: la demanda de servicios recreativos, Madrid, McGraw-Hill.

Martínez-Alier, J. (1992): Obstáculos distributivos contra la política ambiental internacional, Información comercial española, 
$N^{\circ} 711$, Madrid, Ministerio de Industria, Secretaría de Estado de Comercio, noviembre.

Pearce, D. y J. Warford (1993): World without End, Oxford, Reino Unido, Oxford University Press.

Rauscher, M. (1994): On ecological dumping, Oxford Economic Papers, vol. 46, special issue, Londres, Oxford University Press

Reed, W. J. (1994): Una introducción a la economía de los recursos naturales y su modelización, D. Azqueta, y A. Ferreiro (eds.), Análisis económico y gestión de recursos naturales, Madrid, Alianza Editorial.

Ross, J. (1996): Treasure of the Costa Grande, Sierra Magazine, San Francisco, California, Sierra Club of San Francisco, agosto.

Rotillon, G. y T. Tazdait (1996): International bargaining in the presence of global environmental change, Environmental and Resource Economics, vol. 8, $\mathrm{N}^{\circ}$ 3, Dordrecht, Países Bajos, Kluwer Academic Publishers.

Schaltegger, S. y T. Thomas (1996): Pollution Added Credit Trading (PACT): New dimensions in emission trading, Ecological Economics, vol. 19, $\mathrm{N}^{\circ} 1$, Amsterdam, Países Bajos, Elsevier Science B.V.

Schulz, C. E. (1996): Trade policy and ecology, Environmental and Resource Economics, vol. 8, № 1, Dordrecht, Países Bajos, Kluwer Academic Publishers.

Sedjo, R. A., J. Wisniewski, A. V. Sample, y J. D. Kinsman (1995): The economics of managing carbon via forestry: Assessment of existing studies, Environmental and Resource Economics, vol. 6, $\mathrm{N}^{\circ}$ 2, Dordrecht, Países Bajos, Kluwer Academic Publishers.

Shafik, N. (1994): Economic development and environmental quality: An econometric analysis, Oxford Economic Papers, vol. 46, special issue, Londres, Oxford University Press

Shah, A. (1995): The Economics of Third World National Parks, Cheltenham, Reino Unido, Edward Elgar.
Shyamsundar, P. y R.A. Kramer (1996): Tropical forest protection: An empirical analysis of the costs borne by local people, Journal of Environmental Economics and Management, vol. 31, $\mathrm{N}^{\circ}$ 2, Nueva York, Academic Press.

Simpson, R. D., R. A. Sedjo y J. W. Reid (1996): Valuing biodiversity for use in pharmaceutical research, Journal of Political Economy, vol. 104, $\mathrm{N}^{\circ} 11$, Chicago, Illinois, The University of Chicago Press.

Stähler, F. (1996): On international compensation for environmental stocks, Environmental and Resource Economics, vol. 8, № 1 , Dordrecht, Países Bajos, Kluwer Academic Publishers.

Sterner, T. (1994): Discounting in a world of limited growth, Environmental and Resource Economics, vol. 4, $\mathrm{N}^{\circ} 5$, Dordrecht, Países Bajos, Kluwer Academic Publishers.

Swanson, T. M. (1993): Regulating endangered species, Economic Policy, $\mathrm{N}^{\circ} 16$, Londres, Cambridge University Press, abril. (1994): The economics of extinction revisited and revised: A generalized framework for the analysis of the problems of endangered species and biodiversity losses, Oxford Economic Papers, vol. 46, special issue, Londres, Oxford University Press.

Van Kooten, G. C., S. C. Binkley y G. Delcourt (1995): Effect of carbon taxes and subsidies on optimal forest rotation age and supply of carbon services, American Journal of Agricultural Economics, vol. 77, $\mathrm{N}^{\circ}$ 2, Ames, Iowa, American Agriculture Economics Association.

Von Amsberg, J. (1993): Project Evaluation and the Depletion of Natural Capital: An Application of the Sustainability Principle, Environment working paper, $\mathrm{N}^{\circ} 56$, Washington, D.C., Banco Mundial, Departamento del Medio Ambiente.

Weitzman, M. L. (1994): On the "environmental" discount rate, Journal of Environmental Economics and Management, vol. 26, $\mathrm{N}^{\circ} 2$, Nueva York, Academic Press. 